\title{
STRESS ANALYSIS OF BOLTED CONNECTION IN SPACE VEHICLES
}

\author{
Alfred Franklin V. \\ Department of Mechanical Engineering, St.Xavier's Catholic College of Engineering, Nagercoil, India. \\ E-mail : frank_vin@yahoo.com
}

\begin{abstract}
Pressure vessels are leak tight containers. They invariably have a flanged bolted connection at least on one end. Bolts apparently take tensile loads while the cylinder is subjected to internal pressure. However the flange has comparatively higher thickness than that of shell and has geometric discontinuity taking place at the flange-shell junction. Due to this the flange will be subjected to a shear force and a bending moment which are in turn resisted by the shell part. The bending moment and shear force even get transmitted to bolts. Hence instead of taking a pure tensile load, the bolts also take bending loads. A comprehensive design approach for this application is given in ASME Boiler and Pressure Vessel Code, Section VIII, Division 1. The corresponding British Standard, PD 5500:2000, and the new European Code, EN 13445, provide a less detailed design approach for these flanges, which ignores the influence of the shell. In this work, a beam theory is utilized to simplify an annular flange into a number of beams, so as to evaluate the bolt stress considering shell-flange interactions. Results obtained have been compared with an approximate analysis. The geometry considered is flat face flange with metal to metal contact outside the bolt circle. In this work the flange is treated as beam comprised of a series of radial beams. The analysis started with an approximation, before commencing detailed analysis. Followed by this the detailed analysis is carried out. From the analysis it has been observed that the contact circle radius increases reasonably as the pressure increases and correspondingly the stress also increases. The stress values agree well with the values of approximate analysis.
\end{abstract}

Key words: pressure vessel, FEA, bolted connections, beam theory, metal to metal contact.

\section{INTRODUCTION}

Pressure vessels are leak tight containers. They invariably have flat or domed ends normally attached to the cylindrical part through a flanged bolted connection at least on one end. Bolts apparently take tensile loads while the cylinder is subjected to internal pressure. However the flange has comparatively higher thickness than that of shell and has geometric discontinuity taking place at the flange-shell junction. Due to this the flange will be subjected to a shear force and a bending moment which are in turn resisted by the shell part. The bending moment and shear force even get transmitted to bolts. Hence instead of taking a pure tensile load, the bolts also take bending loads. In such complex state of stress, it become essential to asses maximum stress experienced by the bolt and hence to design the joint effectively. In this work, a beam theory described on reference [1] is utilized to simplify an annular flange into a number of beams, so as to evaluate the bolt stress. Results obtained have been compared with an approximate analysis which is also presented in reference [1].

\section{GEOMETRY OF THE JOINT}

The geometry considered is flat face flange with metal to metal contact outside the bolt circle. This is for service under internal pressure. The flanges are bolted directly together. Pipe or vessel wall is welded to the flange ring in such a manner that flange and shell react as a continuous structure. In this work the flange is treated as beam comprised of a series of radial beams. Typical flat face flange is shown in Fig. 1.

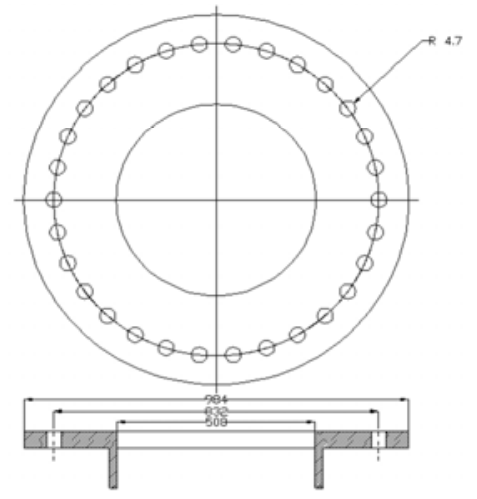

Fig. 1. Views of Flat Face Flange

\section{DESIGN APPROACHES}

In one of the approaches, flange ring could be treated as an annular plate acted upon by an appropriate system of forces. Though the flanges are in contact beyond bolt circle, the contact circle is variable and depends upon many things including amount of pre-stress applied to the bolts and the internal pressure. Hence the approach is unwieldy. In another approach the flange ring may be treated as being comprised of a series of discrete, radial beams with forces applied at the flange-shell junction, bolt circle and bearing circle. Logically the radial beam should be considered as trapezoids of unit width $(25.4 \mathrm{~mm})$ at the flange-shell junction. Mathematically this approach is also unwieldy since ultimately it becomes necessary to locate the position of the bearing circle. Fig. 2 shows the view of a single radial beam. 


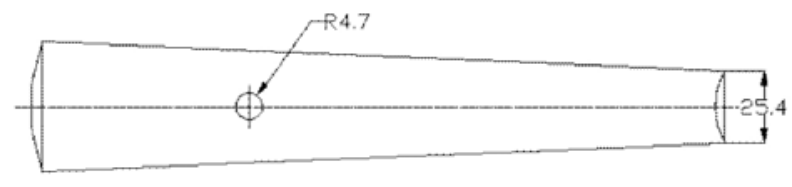

Fig. 2. Radial beam

The problem can be simplified further by modifying the trapezoidal element to an equivalent beam uniformly wide 'c' from the bolt to the bolt circle and uniformly wide 'a' from bolt circle to outside diameter. Fig. 3 shows the modified trapezoidal beam.

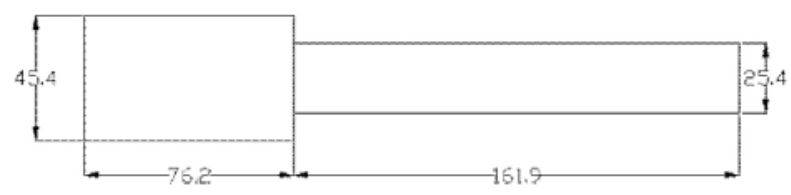

Fig. 3. Modified trapezoidal beam

The flanges support each other beyond the bolt circle by distributed reactive forces, the centroid of which is equivalent to the simple support. Fig. 4 shows this configuration. Finding the location of the centroid is an essential step in designing flat face flanges. The radial distance of centroid from bolt circle (b) decides the moment and shear force at the flange- shell junction and in turn the bolt and flange stresses.

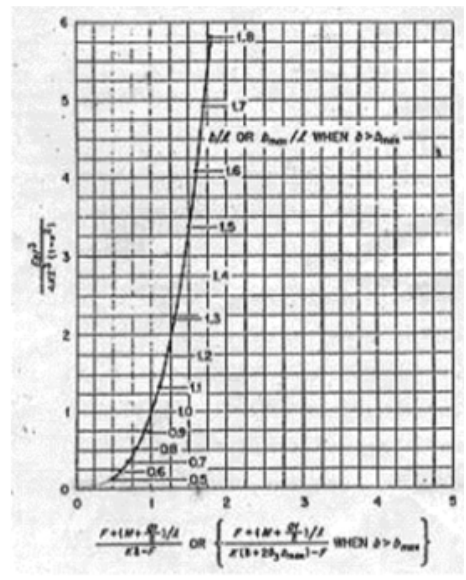

Fig. 4. Curve for finding $b$

\section{APPROXIMATE ANALYSIS}

Flange design is fundamentally the process of trial and error. However, the number of errors reduced significantly by having a goal first approximation, before commencing detailed analysis. Such an approximation can be made by disregarding the interaction between shell and flange which is equivalent to setting moment and shear force equal to zero. Following is an approximation method. $R_{m}, l$, $b_{\max }$ and $h$ have been selected as follows:
Step $1 \quad R_{m}=254 \mathrm{~mm} ; \quad I=161.93 \mathrm{~mm} ; b_{\max }=76.2$ $\mathrm{mm} ; \mathrm{h}=12.7 \mathrm{~mm}$

Step 2 Total number of bolts is taken as $\mathrm{n}=30$

Step 3 Minimum area per bolt is calculated as

$$
\mathrm{A}=\frac{\mathrm{PR}_{\mathrm{m}}{ }^{2}\left(1+\frac{\mathrm{I}}{\mathrm{b}_{\max }}\right)}{2 \sigma_{\mathrm{b}} \mathrm{N}\left(\mathrm{R}_{\mathrm{m}}+\mathrm{I}\right)}=88.129 \mathrm{~mm}^{2} \text {. }
$$

Where,

$\mathrm{P}=0.6897 \mathrm{~N} / \mathrm{mm}^{2} ; \sigma_{\mathrm{b}}=165.03 \mathrm{~N} / \mathrm{mm}^{2}$

Step 4 Bolt M16 is selected to have cross sectional area greater than $88.129 \mathrm{~mm}^{2}$

Step5

$\mathrm{N}^{\prime}$ is calculated.

$$
\begin{aligned}
& \mathrm{N}^{\prime}=\mathrm{N}\left(\frac{\mathrm{R}_{\mathrm{m}}+\mathrm{I}}{\mathrm{R}_{\mathrm{m}}}\right)=0.478 \text { bolt } / \text { beam. } \\
& \mathrm{N}=\frac{\mathrm{n}}{\prod\left(2 \mathrm{R}_{\mathrm{m}}+2 \mathrm{l}\right)}=0.0115 \text { bolt } / \mathrm{mm}
\end{aligned}
$$

Step 6 Stiffness $\mathrm{K}$ is calculated as

$$
\begin{aligned}
& \mathrm{K}=\frac{\mathrm{N}^{\prime} \mathrm{AE}_{\mathrm{b}}}{\mathrm{I}_{\mathrm{e}}}=2.389 \times 10^{5} \mathrm{~N} / \mathrm{mm} / \text { beam } \\
& \mathrm{I}_{\mathrm{e}}=2 \mathrm{t}+\frac{\mathrm{d}}{2}+2 \mathrm{t}_{\mathrm{w}}=57.569 \mathrm{~mm}
\end{aligned}
$$

where

New area at least diameter of standard bolt, $\mathrm{A}=143.871 \mathrm{~mm}^{2} ; \mathrm{E}, \mathrm{E}_{\mathrm{b}}=2 \times 10^{5} \mathrm{~N} / \mathrm{mm}^{2} ;$ Nominal bolt diameter, $\mathrm{d}=16 \mathrm{~mm}$; Thickness of washer, $\mathrm{t}_{\mathrm{w}}=3.175 \mathrm{~mm}$.

Step 7 Pre-stress is fixed as $\sigma_{\mathrm{I}}=0.8 \sigma_{\mathrm{b}}$ which equals $132.024 \mathrm{MPa}$.

Step 8 Deflection $\delta$ is calculated as $\delta=\frac{\sigma_{\mathrm{I}} \mathrm{I}_{\mathrm{e}}}{\mathrm{E}_{\mathrm{b}}}=0.038 \mathrm{~mm}$

Step9 Flange thickness is calculated as

$$
\begin{aligned}
& \mathrm{t}=1.1 \mathrm{R}_{\mathrm{m}}\left(\frac{3 \mathrm{Pl}}{\sigma_{\mathrm{f}}(1-\mathrm{Nd})\left(\mathrm{R}_{\mathrm{m}}+\mathrm{I}\right)}\right)^{0.5}= \\
& 21.609 \mathrm{~mm} \\
& \sigma_{\mathrm{f}}=165.03 \mathrm{~N} / \mathrm{mm}^{2} ; \mathrm{d}=16 \mathrm{~mm} ;
\end{aligned}
$$

Step 10 In order to calculate $b / I$ and hence $b$, following parameters are calculated.

$$
\begin{aligned}
\text { Say } x & =\frac{F}{K \delta-F}=0.3246 \\
y & =\frac{\text { Eat }^{3}}{4 \mathrm{KI}^{3}\left(1-v^{2}\right)}=0.0266 \\
F & =\frac{P R_{m}}{2}=87.595 \mathrm{~N} / \mathrm{mm}
\end{aligned}
$$

Read of value of $b / I=0.3$. ( from graph, figure 5)

$$
\mathrm{b}=\mathrm{I} \times 0.3=48.5775 \mathrm{~mm}
$$

Step 11 Bolt load B is calculated as

$$
\mathrm{B}=\mathrm{F}\left(1+\frac{\mathrm{l}}{\mathrm{b}}\right)=9641.283 \mathrm{~N} / \mathrm{beam}
$$


Step12 Approximate operating bolt stress is calculated as

$$
\sigma_{\mathrm{B}}=\frac{\mathrm{B}}{\mathrm{N}^{\prime} \mathrm{A}}=140.133 \mathrm{~N} / \mathrm{mm}^{2}
$$

\section{DETAILED ANALYSIS}

In this analysis it is assumed that contact of flanges takes place at a radius between bolt circle radius and flange outer radius.

i.e. $b<b_{\max }$

Although the flexural behavior of the flange can be described by beam analogy, circumferential continuity of the flange cannot be ignored. The outward, radial deflection of the flange at the point where itjoints the shell is:

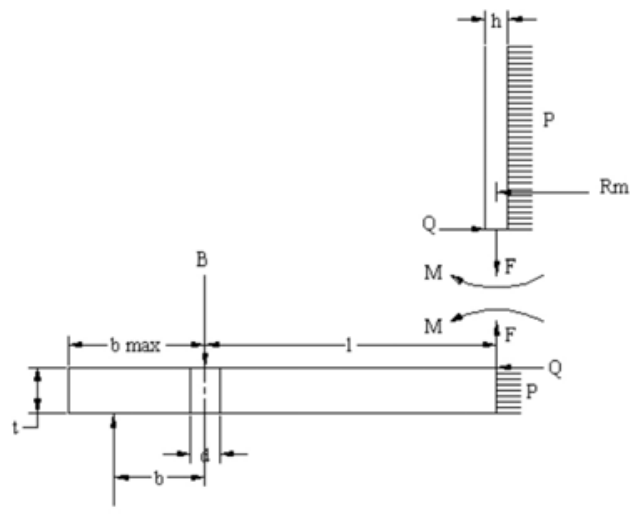

Fig. 5. Free-body diagram of a flange

$$
\begin{aligned}
\mathrm{u}_{1}=\mathrm{K}_{\mathrm{A}}+\mathrm{K}_{\mathrm{B}} \mathrm{Q}+\theta_{1} \frac{\mathrm{t}}{2} ; \quad \mathrm{b}<\mathrm{b}_{\max } \\
\mathrm{K}_{\mathrm{A}}=\frac{\mathrm{PR}_{\mathrm{m}}}{\mathrm{E}}\left[\frac{\left(\mathrm{R}_{\mathrm{m}}+\mathrm{L}\right)^{2}+\mathrm{R}_{\mathrm{m}}{ }^{2}}{\left(\mathrm{R}_{\mathrm{m}}+\mathrm{L}\right)^{2}-\mathrm{R}_{\mathrm{m}}{ }^{2}}+0.3\right] \\
\mathrm{K}_{\mathrm{B}}=\frac{\mathrm{PR}}{\mathrm{tE}}\left[\frac{\left(\mathrm{R}_{\mathrm{m}}+\mathrm{L}\right)^{2}+\mathrm{R}_{\mathrm{m}}{ }^{2}}{\left(\mathrm{R}_{\mathrm{m}}+\mathrm{L}\right)^{2}-\mathrm{R}_{\mathrm{m}}{ }^{2}}+0.3\right]
\end{aligned}
$$

Fig. 5 is free-body diagram of the equivalent beam which is being used to describe the flexural behavior of the flange. The slope of the beam at the flange-shell junction, which is given by the area under the M/EI diagram, is:
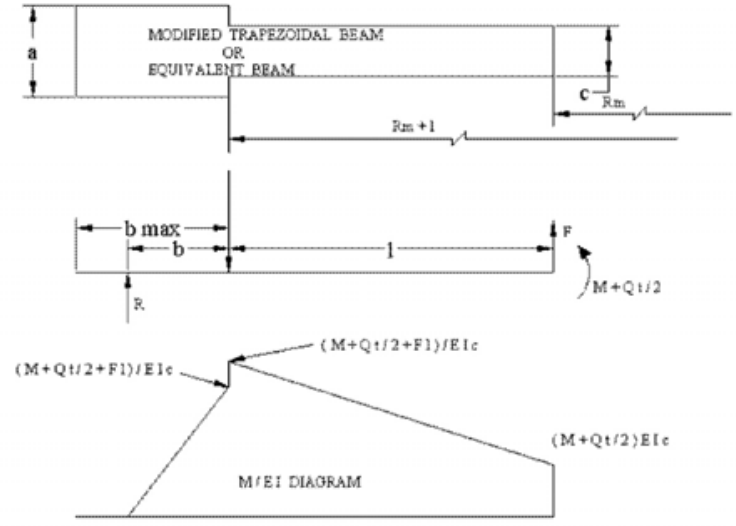

Fig. 6. Free-body diagram of equivalent beam

$$
\begin{aligned}
& \left.\theta_{1}-\frac{6\left(1-v^{2}\right)}{\mathrm{Ext}^{3}}[\mathrm{~F})^{2}\left(\frac{\mathrm{a}}{\mathrm{c}}+\frac{\mathrm{b}}{\lambda}\right)+\left(\mathrm{M}+\frac{\mathrm{Qt}}{2}\right)(\mathrm{\lambda})\left(\frac{2 \mathrm{a}}{\mathrm{c}}+\frac{\mathrm{b}}{\lambda}\right)\right] \mathrm{b}<\mathrm{b}_{\max } \\
& \frac{\left(R_{m}+\lambda+\frac{b_{\max }}{2}\right)}{R_{m}} \\
& c=\frac{\left(R_{m}+\frac{\lambda}{2}\right)}{R_{m}} \\
& \text { or }
\end{aligned}
$$

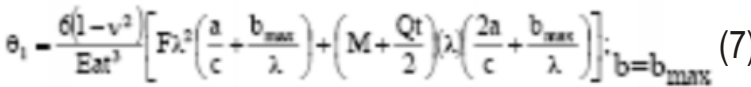

The term 1- $v^{2}$ appears in the flange equations since continuity in the circumferential direction must be maintained during bending.

The forces on the shell are shown in Fig .6 The outward, radial deflection of the shell due to $M$ and $Q$ [2] plus the uniform expansion due to the design pressure is:

$$
\begin{aligned}
\mathrm{u}_{\mathrm{cyl}}= & \frac{2 \mathrm{R}_{\mathrm{m}}{ }^{2} \beta^{2}}{\mathrm{Eh}}(\mathrm{M})-\frac{2 \mathrm{R}_{\mathrm{m}}{ }^{2} \beta}{\mathrm{Eh}}(\mathrm{Q})+\mathrm{u}_{2} \\
\beta= & {\left[\frac{3\left(1-\mathrm{v}^{2}\right)}{\mathrm{R}_{\mathrm{m}}^{2} \mathrm{~h}^{2}}\right]^{0.25} } \\
\mathrm{u}_{2}= & \frac{\mathrm{PR}_{\mathrm{m}}{ }^{2}\left(1-\frac{v}{2}\right)}{\mathrm{E}_{\mathrm{h}}}
\end{aligned}
$$

The counterclockwise rotation of the shell due to $M$ and $Q$ [4] is 


$$
\theta_{c y l}=\frac{2 R_{m}{ }^{2} \beta^{2}}{E h}(Q)-\frac{4 R_{m}{ }^{2} \beta^{3}}{E h}(M)
$$

Equations (1) and (8) are equated to represent deflection compatibility at the flange-shell junction in terms of $M$ and $Q$. Similarly, (4) and (11) are equated to express slope compatibility when $b<b_{\max }$. The simultaneous solution of the compatibility equations yields :

$$
\begin{aligned}
& \mathrm{M}=\frac{\mathrm{Eh}}{2 \beta^{2} \mathrm{R}_{\mathrm{m}}{ }^{2}}\left[\mathrm{u}_{2}-\mathrm{u}_{1}-\frac{\theta_{1}}{\beta}\right] ; \quad \mathrm{b}<\mathrm{b}_{\max } \\
& \mathrm{Q}=\frac{\mathrm{Eh}}{\mathrm{R}_{\mathrm{m}}^{2} \beta}\left[\mathrm{u}_{2}-\mathrm{u}_{1}-\frac{\theta_{1}}{2 \beta}\right] ; \quad \mathrm{b}<\mathrm{b}_{\max }
\end{aligned}
$$

Equations (12) and (13) are solved for a first approximation of $M$ and $Q$, assuming $\theta_{1}=0$ and $u_{1}=K_{A}$.

The forgoing equation cannot be solved directly since $\theta_{1}$ involves dimension $b$ which is still unknown. The next section shows how $b$ is determined by means of a boltflange compatibility analysis.

The operating bolt load /beam is found by using the free-body diagram of Fig. 6 and taking moments about R. The equations for $\mathrm{B}$ become:

$$
\mathrm{B}=\mathrm{F}\left(1+\frac{\lambda}{\mathrm{b}}\right)+\left(\mathrm{M}+\frac{\mathrm{Qt}}{2}\right)\left(\frac{1}{\mathrm{~b}}\right) ; \mathrm{b}<\mathrm{b}_{\max }
$$

Referring to Fig.6, the deflection of the flange at the bolt circle is:

$$
\mathrm{y}_{\text {flange }}=\frac{2 \mathrm{~b}^{2}\left(\mathrm{M}+\frac{\mathrm{Qt}}{2}+\mathrm{F} \lambda\right)}{\mathrm{Eat}^{3}}
$$

When pressure is applied to a flanged closure, the bolts do not elongate until the pre-tensioning load $(\mathrm{K} \delta)$ is exceeded; further, the elongation will be distributed evenly between both flanges. One-half the total elongation caused by the application of the design pressure is:

$$
\frac{1}{2} \mathrm{y}_{\text {bolt }}=\frac{1}{2}\left(\frac{\mathrm{B}}{\mathrm{K}}-\delta\right)
$$

Equating equations (15) and (16), rearranging, and simplifying by using equation (14) yields:

$$
\left(\frac{\mathrm{b}}{1}\right)^{3}=\frac{\mathrm{Eat}^{3}}{\mathrm{AK} \lambda^{3}\left(1-v^{2}\right)}\left[1-\frac{(\mathrm{K} \delta-\mathrm{F}) \mathrm{b} / \lambda}{\mathrm{F}+\left(\mathrm{M}+\frac{\mathrm{Qt}}{2}\right) \frac{1}{\lambda}}\right]
$$

Computation of bolt stress is iterative in nature. Initial assumption are $\theta_{1}=0$ and $u_{1}=K_{A}$ in equation (1). Using equations (12) and (13) first approximation of $M$ and $Q$ are calculated. Corresponding value of $b$ is obtained by solving non-linear equation (17) by Newton-Raphson iterative scheme. Now $Q_{1}$ and $u_{1}$ can be calculated with the values available above. The procedure is repeated till the values of $K \& M$ are converged and the corresponding value of $b$ is obtained.

\section{RESULTS AND DISCUSSION}

A program is written in ' $\mathrm{C}$ ' for carrying out an analysis which is highly iterative in nature. Since bolt stress depends on the contact circle which is unknown, the complexity is more. Hence the value of moment $\mathrm{M}$ and $\mathrm{Q}$ which are dependent on the bolt circle radius are to be evaluated in an iterative way, for each pressure. The analysis is tried for given pressure vessel with the pressure varying from $0.1 \mathrm{MPa}$ to $0.7 \mathrm{Mpa}$ in steps of $0.1 \mathrm{Mpa}$ in order to have a feel of variation of $b$. However, the parameters could not be stabilized at lower pressures. Further the results obtained in a range of pressures possible. The results obtained are presented in Table 1. Fig. 7 shows the detailed analysis results.

Table 1. Comparison of results from detailed analysis

\begin{tabular}{|cccc|}
\hline $\begin{array}{c}\text { Pressure, } \\
\mathrm{P} \\
\mathrm{MPa}\end{array}$ & $\begin{array}{c}\mathrm{b} \\
\text { (Detailed } \\
\text { analysis), } \\
\mathrm{mm}\end{array}$ & $\begin{array}{c}\text { Bolt } \\
\text { stress, } \sigma_{\mathrm{b}}, \\
\text { (Detailed } \\
\text { analysis), } \\
\text { MPa }\end{array}$ & $\begin{array}{c}\text { Bolt } \\
\text { stress, } \sigma_{\mathrm{b}} \\
\text { (Approxi } \\
\text { mate } \\
\text { analysis), } \\
\text { MPa }\end{array}$ \\
\hline 0.60 & 39.12 & 145.02 & 140.81 \\
0.61 & 39.37 & 146.65 & 138.84 \\
0.62 & 39.62 & 148.20 & 136.90 \\
0.63 & 39.88 & 149.79 & 135.20 \\
0.64 & 40.13 & 151.40 & 133.64 \\
0.65 & 40.39 & 153.02 & 132.22 \\
0.66 & 40.64 & 154.66 & 130.93 \\
0.67 & 40.89 & 156.31 & 129.74 \\
0.68 & 40.89 & 157.98 & 128.65 \\
0.69 & 41.15 & 159.67 & 127.66 \\
0.7 & 41.40 & 161.37 & 126.73 \\
\hline
\end{tabular}




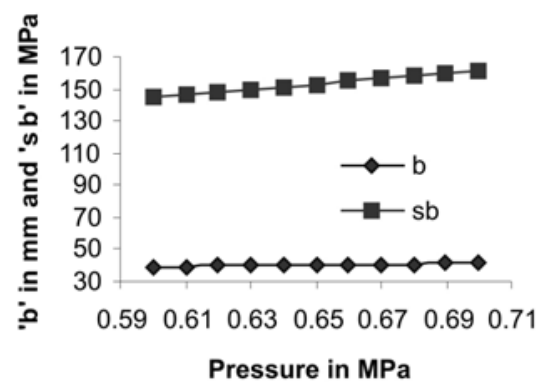

Fig. 7. Detailed analysis results

\section{CONCLUSION}

Determination of bolt stress in a pressure vessel is not straight forward due to the complexity in load contributions. An attempt is made to evaluate the bolt stress for the given configuration of flat face flange using a finer technique which is highly iterative in nature. However this needs further validation through finite element analysis which is planned for further work.

\section{NOMENCLATURE}

\begin{tabular}{|c|c|c|}
\hline $\begin{array}{l}\text { Sym } \\
\text { bol }\end{array}$ & Meaning & Unit \\
\hline A & $\begin{array}{l}\text { cross-sectional area of one } \\
\text { bolt at root of thread or } \\
\text { section of least diameter }\end{array}$ & sq. mm \\
\hline a & $\begin{array}{l}\text { width of beam between bolt } \\
\text { circle and outside diameter }\end{array}$ & $\mathrm{mm}$ \\
\hline B & $\begin{array}{l}\text { calculated operating bolt } \\
\text { load per beam at design } \\
\text { pressure }\end{array}$ & N/beam \\
\hline $\mathrm{b}$ & $\begin{array}{l}\text { Distance from bolt circle to } \\
\text { flange-spacer or flange- } \\
\text { flange bearing circle }\end{array}$ & $\mathrm{mm}$ \\
\hline $\mathrm{b}_{\max }$ & $\begin{array}{l}\text { Distance from bolt circle to } \\
\text { the outer edge of flange but } \\
\text { not to exceed distance to } \\
\text { outer edge of spacer }\end{array}$ & $\mathrm{mm}$ \\
\hline $\mathrm{c}$ & $\begin{array}{l}\text { Width of beam between } \\
\text { mid-radius of shell and bolt } \\
\text { circle }\end{array}$ & $\mathrm{mm}$ \\
\hline d & diameter of bolt hole & $\mathrm{mm}$ \\
\hline $\mathrm{E}, \mathrm{E}_{\mathrm{b}}$ & $\begin{array}{l}\text { Modulus of elasticity of } \\
\text { flange material and bolt } \\
\text { material, respectively }\end{array}$ & $\mathrm{N} / \mathrm{mm}^{2}$ \\
\hline $\mathrm{F}$ & Axial load due to pressure & $\mathrm{N} / \mathrm{mm}$ \\
\hline h & Shell thickness & $\mathrm{mm}$ \\
\hline K & bolt stiffness & $\mathrm{N} / \mathrm{mm} /$ beam \\
\hline $\mathrm{K}_{\mathrm{A}}$ & $\begin{array}{l}\text { Outward radial deflection of } \\
\text { flange due to pressure }\end{array}$ & $\mathrm{mm}$ \\
\hline
\end{tabular}

\begin{tabular}{|c|c|c|}
\hline $\mathrm{K}_{\mathrm{B}}$ & $\begin{array}{l}\text { Factor so that } \mathrm{K}_{\mathrm{B}} \mathrm{Q} \text { is } \\
\text { outward radial deflection of } \\
\text { flange due to shear force } \mathrm{Q}\end{array}$ & $\mathrm{mm}^{2} / \mathrm{N}$ \\
\hline $\mathrm{I}_{\mathrm{e}}$ & $\begin{array}{l}\text { Effective strain length of } \\
\text { bolts and studs }\end{array}$ & $\mathrm{mm}$ \\
\hline $\mathrm{L}$ & width of flange & $\mathrm{mm}$ \\
\hline I & $\begin{array}{l}\text { distance from mid-thickness } \\
\text { of shell to bolt circle }\end{array}$ & $\mathrm{mm}$ \\
\hline M & $\begin{array}{l}\text { meridional bending moment } \\
\text { at flange-shell junction }\end{array}$ & $\begin{array}{l}\mathrm{N}- \\
\mathrm{mm} / \mathrm{mm}\end{array}$ \\
\hline $\mathrm{N}$ & number of bolts $/ \mathrm{mm}$ of & $\mathrm{mm}^{-1}$ \\
\hline$N^{\prime}$ & number of bolts per beam & - \\
\hline$P$ & design pressure & $\mathrm{N} / \mathrm{mm}^{2}$ \\
\hline Q & $\begin{array}{l}\text { shear force at flange-shell } \\
\text { junction }\end{array}$ & $\mathrm{N} / \mathrm{mm}$ \\
\hline $\mathrm{R}_{\mathrm{m}}$ & $\begin{array}{l}\text { radius to mid-thickness of } \\
\text { shell }\end{array}$ & $\mathrm{mm}$ \\
\hline $\mathrm{t}$ & thickness of flange & $\mathrm{mm}$ \\
\hline $\mathrm{t}_{\mathrm{s}}$ & thickness of spacer & $\mathrm{mm}$ \\
\hline $\mathrm{u}_{1}$ & $\begin{array}{l}\text { total outward radial } \\
\text { deflection of flange at } \\
\text { flange-shell junction }\end{array}$ & $\mathrm{mm}$ \\
\hline $\mathrm{u}_{2}$ & $\begin{array}{l}\text { outward radial deflection of } \\
\text { shell due to pressure }\end{array}$ & $\mathrm{Mm}$ \\
\hline$v$ & Poisson's ratio & - \\
\hline$\theta_{1}$ & $\begin{array}{l}\text { slope of flange at junction } \\
\text { of shell when } b \leq b_{\max }\end{array}$ & Radians \\
\hline$\beta$ & factor in shell equations & - \\
\hline$\delta$ & $\begin{array}{l}\text { total initial strain in a bolt } \\
\text { due to pre-tensioning }\end{array}$ & $\mathrm{Mm}$ \\
\hline$\sigma_{\mathrm{b}}$ & allowable bolt stress & $\mathrm{N} / \mathrm{mm}^{2}$ \\
\hline$\sigma_{\mathrm{B}}$ & $\begin{array}{l}\text { calculated operating bolt } \\
\text { stress at design pressure }\end{array}$ & $\mathrm{N} / \mathrm{mm}^{2}$ \\
\hline$\sigma_{\mathrm{f}}$ & allowable flange stress & $\mathrm{N} / \mathrm{mm}^{2}$ \\
\hline$\sigma_{\mathrm{I}}$ & $\begin{array}{l}\text { initial bolt stress due to pre- } \\
\text { tensioning }\end{array}$ & $\mathrm{N} / \mathrm{mm}^{2}$ \\
\hline$\sigma_{\mathrm{C}}$ & $\begin{array}{l}\text { calculated circumferential } \\
\text { stress in shell at flange-shell } \\
\text { junction (membrane plus } \\
\text { bending) }\end{array}$ & $\mathrm{N} / \mathrm{mm}^{2}$ \\
\hline$\sigma_{\mathrm{H}}$ & $\begin{array}{l}\text { calculated longitudinal } \\
\text { stress in shell at flange-shell } \\
\text { junction(membrane plus } \\
\text { bending stress), }\end{array}$ & $\mathrm{N} / \mathrm{mm}^{2}$ \\
\hline$\sigma_{\mathrm{R}}$ & $\begin{array}{l}\text { calculated radial stress in } \\
\text { flange }\end{array}$ & $\mathrm{N} / \mathrm{mm}^{2}$ \\
\hline$\sigma_{\mathrm{T}}$ & $\begin{array}{l}\text { Calculated tangential stress } \\
\text { in flange }\end{array}$ & $\mathrm{N} / \mathrm{mm}^{2}$ \\
\hline
\end{tabular}




\section{REFERENCES}

[1] R. W. Schneider, 1968, "Flat Face Flanges with Metal-To-Metal Contact Beyond the Bolt Circle" J. of Engineering for Power, pp. 867-873.

[2] Timoshenko, S., 1940, Theory of Plates and Shells, McGraw-Hill, pp.389-395.

[3] M. Abid, D.H. Nash, 2004, "A parametric study of metal-to-metal contact flanges with optimized geometry for safe stress and no-leak conditions"Int. J. Pressure Vessels and Piping, (81): pp.67-74.

[4] E.O. Waters, R.W Schneider, 1969, "AxiSymmetric, Non-Identical, Flat Face Flanges With Metal-to-Metal Contact Beyond the Bolt Circle", J. of Engineering for Industry, pp.883-890.
[5] R.W Schneider, E.O. Waters, 1979, "Pressure Vessel and Piping Codes" J. of Pressure Vessel Technology, (101) pp.87-94.

[6] Ming Zhang, Yanyao Jiang, Chu-Hwa Lee, 2007,"Finite Element Modeling of SelfLoosening of Bolted Joints", J. of Mechanical Design, (129):pp.218-226.

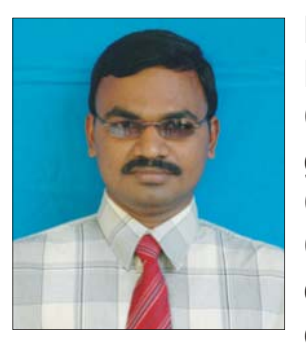

Mr. V. Alfred Franklin is a Senior Lecturer at St. Xavier's Catholic College of Engg. Nagercoil. A postgraduate from Anna University, Chennai, and his specialization is Computer-aided Design. He has over nine years of teaching experience. 